\title{
Aventuras e Perambulações Pela são PaUlo de Fins do SÉCUlo XIX
}

\author{
Resenha do livro: Fraya Frehse. O Tempo das Ruas na São Paulo de Fins do \\ Império. São Paulo: Editora da Universidade de São Paulo, 2005.
}

por Nelson Aprobato Filho'

Desde sua fundação a cidade de São Paulo tem sido objeto constante de observação, diletantismo, pesquisa. São inúmeras as análises, descrições, relatos, opiniões, crônicas e memórias referente às singularidades, contingências e características desse complexo espaço urbano.

O dia estava delicioso, e a pureza do horizonte imaculado dava um brilho luminoso ao espetáculo que se desenrolava diante de nossos olhos.

No extremo de uma paisagem infinita, acidentada com a elevação das colinas e o leito de aveludadas planícies, viam-se transparecer por entre a verdura, as torres das igrejas e as paredes alvas das habitações da cidade de São Paulo, reclinada aos pés do rio Tamanduateí e do ribeirão Anhagabaú, envolta ainda nesse manto de ligeiros vapores com que a natureza desperta de seu sono nas primeiras horas da manhã.

Entramos finalmente em São Paulo pelo lugar chamado Brás. É um dos arrabaldes mais belos e concorridos da cidade, já notável pelas elegantes casas de campo e deliciosas chácaras onde residem muitas famílias abastadas, ao lado, todavia, de alguns casebres e ranchos menos aristocráticos, mas que nem por isso deixam de formar um curioso contraste. ${ }^{2}$

Relatos como esse é freqüente entre os registros de visitantes que por São Paulo passaram durante o século XIX. A paisagem natural na qual estava envolvida a cidade, o amplo panorama visual que a inexistência de altas construções possibilitava e a baixa densidade demográfica que dava às suas ruas uma relativa tranqüilidade, exercia forte impressão a quem nela chegasse. Era comum, como ocorrera a Zaluar entre 1860 e 1861, essa espécie de deslumbramento perceptivo frente a uma localidade marcada ainda por fortes elementos naturais. Spix e Martius, percorrendo-a em 1817, declararam que eram "belos os arredores de São Paulo" e que o viajante, estando em seus pontos mais elevados, teria "uma extensa vista sobre a região, cujos alternados outeiros e vales, matos ralos e

\footnotetext{
${ }^{1}$ Doutorando em História Social - Departamento de História da Faculdade de Filosofia, Letras e Ciências Humanas-USP. Bolsista FAPESP.

2 Zaluar, Augusto-Emilio. Perigrinação pela Província de São Paulo (1860-1861). São Paulo: Livraria Martins Editora, 1954, pp. 123-4.
} 
suaves prados verdejantes oferecem todos os encantos da amável natureza". 3 Saint-Hilaire, visitando-a em 1819, afirmou ser a cidade "incontestavelmente a mais bela de todas por mim visitadas desde que estava no Brasil." do palácio [do Governo] que dão para os campos descortina-se uma vista maravilhosa (...). Abaixo da cidade vê-se o Tamanduateí, que vai coleando por uma campina semi-alagada (novembro), no fim do qual se estendem os pastos pontilhados de tufos de árvores baixas". 5 O escritor mineiro Bernardo Guimarães, natural de Ouro Preto, viveu na Capital da Província entre os anos de 1846 e 1852. Para ele, nessa época, São Paulo conservava ainda “certos laivos de sua primitiva simplicidade" e não havia segundo sua visão, "nada mais risonho e pitoresco do que esses vargedos do Tietê, que no tempo das águas se convertem em labirinto de lagoas e canais, no seio dos quais emergem ilhas cobertas de verdejantes balsas com suas casinhas meio sumidas entre moitas...”. Ao referir-se, como Zaluar, a região do Brás, extasia-se ante a "vasta e formosa perspectiva [que] oferece esse bairro, visto do terraço do convento do Carmo... é a mais deliciosa e encantadora que se pode imaginar. A capela de São Brás com seu campanário Branco e aquelas casas dispersam pela planície e exalam como um perfume idílico, que enleva a imaginação..." ${ }^{6}$ No final do século, por volta do ano de 1884, outro viajante, Christopher Columbus Andrews, cônsul geral norte-americano, esteve em São Paulo e declarou:

é a mais formosa e importante de todas as cidades do interior do Brasil, (...). Está situada nas elevadas e amenas margens do rio Tietê, que não é muito maior que um riacho. Em qualquer estação do ano, as árvores de copas verdes, algumas palmeiras entre claras paredes, telhados vermelhos e torres de velhas igrejas, compõem um aspecto impressionante. Olhando-se da cidade em direção ao rio, vê-se que a margem oposta é razoavelmente povoada e mais além há uma grande extensão de terra semelhante a um prado, que após uma distância de oito ou dez milhas encontra-se uma cadeia de verdes colinas. É nesta parte baixa e nova da cidade que se encontra o Jardim Público. ${ }^{7}$

A São Paulo percebida e descrita por esses homens guardava ainda diversas características da vila original fundada em 1554 pelos jesuítas. Geográfica, política e economicamente, seu principal centro continuava localizado no topo de uma colina escarpada cercada a oeste pelo riacho Anhagabaú, a leste pelo pântano do Tamanduateí e a

\footnotetext{
${ }^{3}$ Spix e Martius. Viagem pelo Brasil. vol. I, Belo Horizonte: Ed. Itatiaia, São Paulo: EDUSP, 1981, p. 144.

${ }^{4}$ Bruno, Ernani Silva. Memória da Cidade de São Paulo. Depoimentos de Moradores e Visitantes, 1553-1958 São Paulo: Prefeitura do Município de São Paulo/DPH, 1981, (Série Registros, n. o 4), p. 38.

${ }^{5}$ Saint-Hilaire, August de. Viagem à Província de São Paulo. Belo Horizonte: Ed. Itatiaia; São Paulo: EDUSP, 1976, p. 130.

${ }^{6}$ Bruno, Ernani Silva. op. cit., p. 64.

${ }^{7}$ Idem, p. 98.
} 
norte pelas várzeas do Tietê. ${ }^{8}$ Por outro lado mantinha também um considerável isolamento dessas partes mais baixas e alagadiças da cidade e, quem a visitasse, transpostos esses "obstáculos", chegaria àquela colina-mirante de onde era possível vislumbrar o panorama natural que enredava os arredores da pequena formação urbana.

É importante notar que Zaluar percebeu a cidade a partir de um outro ângulo e de uma perspectiva inversa daquela dos demais visitantes anteriormente citados. Enquanto esses a observaram e a descreveram de seu ponto mais alto e central, de sua zona mais privilegiada, Zaluar a percorreu e a visualizou inicialmente da direção oposta, ao longe, de baixo, do nível dos rios e pântanos, das ruas do Brás. Contudo, há que se levar em conta a distância que o separava da cidade, distância essa que interpunha a realidade de sua visão, provavelmente distorcendo-a, um difuso "manto de ligeiros vapores". À medida que foi se introduzindo na fragmentária e pobre materialidade urbana, aquele fugaz manto dilui-se e, em seu lugar, surgiu uma espécie de aura de estranhamento que não mais lhe ofuscava o olhar, mas sim sua própria compreensão sobre a localidade, o seu íntimo desejo projetado de uma São Paulo idealizada. Ao transitar pelo Brás, rumo a colina central, Zaluar sente certo incômodo causado pelos aspectos externos de humildes habitações, de toscas construções. Como que para amenizar esse sentimento afirma que esses elementos formavam - talvez ao pitoresco de sua percepção visual - "um curioso contraste" com as chácaras abastadas da região. Vistos de cima e a distância, camuflados entre compacta vegetação, os tais "casebres e ranchos" talvez até se tornassem imperceptíveis e não alterassem o "prazer" do olhar. Vistos de perto poderiam magoar as sensibilidades mais delicadas.

Quais foram as contingências históricas que transformaram de maneira profunda, tanto esse panorama natural de rara e exuberante beleza como as atitudes e percepções humanas?

A partir de 1870 iniciava-se na cidade de São Paulo um processo de grandes transformações urbanas e socioculturais. Em 1882 desembarcava na capital paulista pela segunda vez e após uma ausência de trinta anos, o carioca Firmo de Albuquerque Diniz. Fugindo em férias de verão do calor que assolava o Rio de Janeiro, o ex-estudante de

\footnotetext{
${ }^{8}$ Sevcenko, Nicolau. Orfeu Extático na Metrópole - São Paulo, Sociedade e Cultura nos Frementes Anos 20. São Paulo: Companhia das Letras, 1992, pp. 106-7.
} 
Direito do Largo São Francisco, da turma de 1852, fica perplexo com a cidade que encontra. "A população" escreveu Diniz, "parece-me tem-se aumentado em muito mais de metade." Os arrabaldes estavam florescentes e os costumes eram outros. A São Paulo apresentava para suas percepções, "o aspecto de uma cidade civilizada, de movimento comercial importante, e oferecendo todos os recursos e comodidades, de que possam precisar seus habitantes e os viajantes." Estarrecido frente a tantas mudanças, declara maravilhado: "não esperava encontrar a Capital, como está: é uma cidade alegre, buliçosa, inquieta, de visível animação: não é mais a silenciosa São Paulo."9

Referindo-se a cidade de 1852 recorda-se que o som do "rodar de um carro despertava a curiosidade: saía-se à janela para ver quem passava; (...)".${ }^{10}$ Contudo em 1882 com o aumento do número de veículos em circulação e a constante aceleração do ritmo cotidiano, ninguém mais se preocupava em ver quem é que se deslocava pela malha urbana. Para este período observa que "constantemente percorrem as ruas em direções diversas grandes carroças, que conduzem carne aos açougues, outras levando mercadorias da cidade às estações das estradas de ferro, outras daí trazendo-as para o centro da Capital; muitas pipas d'água, umas com hortaliças, outras com frutas, outras transportando garrafas de cerveja e licores nacionais." $" 11$ Em determinados momentos esse movimento chegava ao clímax e despertava outra ordem de sentimentos e percepções, outros graus de compreensão:

Durante certas horas do dia já o incessante rodar de carros e carroças torna-se incômodo a quem não está habituado; ao antigo silêncio sucedeu esse concerto, pouco agradável, de sons produzidos pelo atrito nas calçadas de tantos veículos de diversas espécies, uns de construção leve e elegante, outros de forma grosseira, pesados e apropriados aos gêneros, a cujo transporte se destinam; uns de duas e outros de quatro rodas; uns puxados por lindos animais, outros por feios, e não poucos por antigos servidores, que apresentam-se com ares de quem pede aposentadoria para entregar-se ao descanso. ${ }^{12}$

Entre as décadas finais do século XIX e as primeiras do XX são introduzidos na cidade de São Paulo elementos até então desconhecidos. Em grande parte "importados" dos EUA e da Europa, e muitos deles provenientes dos resultados da Revolução CientíficoTecnológica, eles fizeram parte das mudanças ecológicas, ambientais e socioculturais

\footnotetext{
${ }^{9}$ Diniz, Firmo de Albuquerque (Junius). Notas de Viagem. São Paulo: Governo do Estado, 1978, (Coleção Paulística, v. 5), (1. ${ }^{a}$ ed. 1882), p. 41.

${ }^{10}$ Idem, p. 38.

11 Idem, ibidem.

${ }^{12}$ Idem, pp. 38-9.
} 
ocorridas na cidade no contexto de seu vertiginoso processo de metropolização. ${ }^{13} \mathrm{~A}$ Revolução Científico-Tecnológica foi marcada a grosso modo pelo surgimento, aperfeiçoamento e difusão de diversos objetos, técnicas e implementos. Dentre a gama de novidades decorrentes da técnica e da ciência modernas destacam-se: o motor a explosão, o avião e a gasolina; a soda cáustica e a eletroquímica; a eletrólise, o alumínio e o níquel; o dínamo, a lâmpada incandescente e as usinas elétricas e hidrelétricas; os transportes públicos mecanizados, o pneu e a bicicleta; a máquina de escrever e o jornal leve e barato; as primeiras fibras sintéticas e a seda artificial; os primeiros plásticos sintéticos e a baquelita; o clorofórmio, os anti-sépticos, o fenol e a assepsia; os corantes, a bacteriologia, a microbiologia e a bioquímica; os antibióticos, as vitaminas e os hormônios; a aspirina e a anestesia; os fertilizantes artificiais, a conservação de alimentos através da esterilização e pasteurização e o processo de estanhagem para alimentos enlatados; os sistemas ferroviários de escala continental e os navios de grande tonelagem; a refrigeração e o comércio internacional de frutas, verduras, carnes, trigo, chá e café. Segundo Geoffrey Barraclough, a Revolução Científico-Tecnológica ou Segunda Revolução Industrial fora desencadeada a partir de 1870 e ficou conhecida como a era do aço, da eletricidade, do petróleo e dos produtos químicos. Ela trouxe em seu bojo a mudança da estrutura da sociedade industrial, a integração e interligação econômica do mundo e o neo-imperialismo do final do século XIX. A principal diferença entre as duas primeiras revoluções industriais foi o impacto ou o efeito desencadeado pela segunda, dos progressos científicos e tecnológicos sobre a "vida e perspectivas das pessoas". ${ }^{14}$

O processo de metropolização de São Paulo e sua inserção na economia mundial é parte e em certa medida, conseqüência dessa revolução. Em poucos anos as paisagens naturais e urbanas da cidade mudaram radical e drasticamente.

O Braz, na tela panorâmica da cidade, visto cá do alto à luz do dia, é uma pincelada berrante de zarcão, onde as tropas insolentes das chaminés das suas fábricas, expellem, numa ejaculação insistente para o alto, mascarando de negro a physionomia do céo, atropelados rolos de fumaça! Tem $\mathrm{o}$ aspecto de um amphiteatro em combustão, fervilhante, gerando em seu seio um monstro apocalyptico!

Todo ele é o progresso em fantástica escalada para o Futuro.

\footnotetext{
${ }^{13}$ Sobre o processo de metropolização da cidade Cf. Sevcenko, Nicolau, op. cit.

${ }^{14}$ Todas as informações sobre a Revolução Científica-Tecnológica Cf. Barraclough, Geoffrey. Introdução à História Contemporânea. São Paulo: Círculo do Livro, s.d, capítulo II.
} 
Estas opiniões em forma de crônica foram escritas por Sylvio Floreal em 1925 e fazem parte de suas "rondas noturnas" pelos bairros e ruas da capital paulista. ${ }^{15}$ O Brás continuava sendo, no conjunto espacial da cidade, um ponto de forte atração sensorial. Porém, o panorama vislumbrado pelo autor nos anos 20, destoava brutalmente daquele percebido pelos viajantes que por São Paulo passaram durante o século XIX.

Num deslocamento inverso ao daquele feito por Zaluar em 1860-1861, que das baixas ruas do Brás encaminha-se para a colina-mirante, Floreal mergulha desta em direção ao fabril e populoso bairro. "Há duas grandes artérias, que centralizando o grosso do comércio, cortam estouvadamente, num paralelismo irritante, esse bairro: a Avenida Rangel Pestana e a rua do Gasômetro. Convergem a elas uma infinidade de pequenas e grandes ruas, ruelas, becos, travessas, e outras monstruosidades desse jaez, intransitáveis, algumas ainda em formação." ${ }^{\prime 6}$ Percorrendo fisicamente esse emaranhado de caminhos, sentido de dentro a "fervilhante combustão" do local, o cronista percebe que os fenômenos que ali ocorriam eram numa escala e dimensão que lhe causavam incômodos, vertigens, uma não muito disfarçada repulsa.

O exagero e o absurdo neste bairro atuam e prosperam num conúbio admirável de entendimento tácito. Ao lado de maltrapilhos e mendigos que pedincham uma fugitiva esmola, cruzam industriais arrogantes e garbosos. Desfilam, em direções opostas, mamalhudas matronas e figurinhas lépidas de costureirinhas. E a vida turbilhona numa mistura incaracterística. (...)

E todas, [ruas, ruelas, becos e travessas] como bocarras impudentes, despejam sobre as duas grandes vias a sua formidável choldra anônima e circulante. E nos dias de trabalho, à cadência redemoinhante da lufa-lufa que retrôa, revira, sarabanda, controla e pinoteia, perpassam lascando o barulho, chicoteando o ar, berros, gritos, vozes, assobios, numa debandada estridente que cloroformiza os ouvidos e verruma os nervos.

Em cada esquina desse bairro, fala-se uma língua estranha e ostenta-se um hábito disparatado. Em cada rua, exibe a sua tradição um povo diferente.

Em cada praça, brincam chusmas de garotos peraltas e desbocados, produto dessa feira de povos. ${ }^{17}$

No conjunto da cidade, historicamente a região do Brás adquiriu particularidades interessantes. "O Brás sempre viu a cidade de baixo para cima, e a cidade teve o privilégio de vê-lo de cima para baixo. No entanto, o que mais caracteriza o Brás é exatamente esse elemento de transitoriedade. O Brás tem desde a sua origem uma vocação centrípeta. Ele é um vetor de irradiação, é um vetor de espiralamento das populações e das mercadorias que a partir do bairro se dirigem a todas as demais direções da cidade.” Para esta população,

\footnotetext{
${ }^{15}$ Floreal, Sylvio. Ronda da Meio Noite. Vicios, misérias e esplendores da cidade de São Paulo. São Paulo: Typographia Cúpulo, 1925.p. 14.

${ }^{16}$ Idem, pp. 112.

${ }^{17}$ Idem, pp. 10-2.
} 
constituída basicamente de imigrantes estrangeiros, "a mobilidade [era] um valor. Enquanto você está se movendo, não pode ser novamente aprisionado num contexto social ou político no qual a sua posição vai ser necessariamente subalterna. E essa é em grande parte a tensão fundamental que há entre a população da cidade nas colinas históricas, nas partes altas e secas, e que é uma população altamente sedentarizada, com relação a uma população cujo principal valor da vida é exatamente o seu desprendimento e a sua mobilidade."18

E foi justamente a questão da mobilidade e do espaço chamado Brás que chamaram a atenção da antropóloga Fraya Frehse.

Sem alarde, promessas miraculosas e apelos publicitários, a Editora da Universidade de São Paulo lançou no mês de abril, o quarto volume com o selo "São Paulo 450 anos". Dentre dezenas de publicações, desiguais em qualidade e temática, lançadas por inúmeras editoras e aclamadas pela imprensa no decorrer de 2004 no "calor" das comemorações do aniversário da cidade, meio que silenciosamente e até de maneira um tanto quanto tímida, o que não deixa de ser um grande mérito em nossa "sociedade do espetáculo", dando seqüência à publicação de textos sobre São Paulo ou mais especificamente após ter editado os livros de Aziz Nacib Ab'Saber, São Paulo ensaios entreveros; de Sarah Feldman, Planejamento e Zoneamento: São Paulo 1947 a 1972; e de Regina Prosperi Meyer, Marta Dora Grostein e Ciro Biderman, São Paulo Metrópole, a EDUSP coloca nas livrarias $O$ Tempo das Ruas na São Paulo de Fins do Império de Fraya Frehse. ${ }^{19}$ Trata-se de uma muito bem cuidada produção que segue a mesma excelente linha editorial dos volumes anteriores. Juntaram-se numa mesma publicação, qualidades nem sempre conciliáveis: conteúdo e forma.

"O fato concreto" sugere Nicolau Sevcenko "é que todo ser humano percebe a cidade de seu locus de enraizamento a partir do qual a cidade adquire o seu sentido". ${ }^{20} \mathrm{O}$ sentido que Fraya Frehse deu à São Paulo, que analisou em seu livro, está diretamente ligado ao locus no qual se colocou para desenvolver sua reflexão: a rua que é um locus volátil, não-linear, vibrante, crítico e criativo por excelência. Está ligado além disso às camadas sociais que escolhera para analisar e compreender nesse espaço urbano: os

\footnotetext{
${ }^{18}$ Sevcenko, Nicolau. "Periferia no Centro". Catálogo da Exposição Brasmitte - Intervenções Urbanas, São Paulo: Grupo de Intervenção Urbana, 1997, pp. 63-4.

${ }^{19}$ Frehse, Fraya. O Tempo das Ruas na São Paulo de Fins do Império. São Paulo: Editora da Universidade de São Paulo, 2005.

${ }^{20}$ Sevcenko, Nicolau. "Periferia no Centro", op. cit., p. 60.
} 
transeuntes anônimos. Está ligado ainda às posturas e atitudes analíticas que assumiu no decorrer da pesquisa: um tipo de antropologia urbana com ênfase no cotidiano e na historicidade, nas múltiplas temporalidades e nas contingências. E está por fim, profundamente ligado tanto ao período que abrange sua investigação, o fim do Império, ou mais especificamente as décadas de 1870 e 1880 como também à sua principal descoberta: o limiar da "opinião pública" e os primeiros traços da "mal entendida" modernidade paulistana. Como se vê, a autora colocou-se numa posição privilegiada para compreender antropologicamente a história da cidade de São Paulo. O resultado, uma dissertação de mestrado transformada agora em livro, possui qualidades substanciais, provocando constantemente seus leitores.

Partindo do mesmo espaço que atraiu irresistivelmente tanto Zaluar como Sylvio Floreal, o Brás e a Várzea do Carmo, em se tratando de uma realidade urbana próxima daquela percebida por Firmo de Albuquerque Diniz, aliás, uma das fontes também utilizada pela autora, Fraya Frehse convida seus leitores para ao lado dela e de alguns transeuntes, seu principal "objeto" de investigação, fazer um "passeio imaginário" por algumas ruas da cidade.

O passeio para o qual convido o leitor é bastante peculiar: é imaginário. Em primeiro lugar porque, se evidentemente nem eu nem o leitor vivenciamos concretamente a São Paulo oitocentista, trata-se aqui de nos juntarmos para que eu o conduza imaginariamente por algumas ruas e becos, ladeiras e largos, várzeas e jardins da cidade, narrando-lhe no caminho o que os transeuntes, também companheiros deste passeio, relatam - nos jornais, nas atas da Câmara Municipal e em fotografias sobre o seu cotidiano nas ruas de fins do Império. ${ }^{21}$

Contudo, Fraya Frehse conseguiu fazer muito mais do que isso. Ao acompanhá-la pelas ruas da São Paulo do final do Império praticamos algo muito mais intenso "real", complexo e interativo do que um simples "turístico" e descomprometido passeio. Ela não nos conduz. Muito melhor do que nos conduzir, o que daria uma idéia meio determinista e “impositiva", ela nos convida, nos apresenta e nos dá total liberdade de movimento. Seu texto e suas propostas antropológicas nos deixam constantemente tentados a perambular por outras ruas, a acompanhar outros ritmos, a dialogar com outros transeuntes, a pensar em outros tempos históricos, a ocupar outros espaços públicos. Fraya possibilita ao leitortranseunte a chance de "escapar" do percurso traçado inicialmente por ela. Em muitas oportunidades, ao invés de acompanhá-la e a seus transeuntes, apenas os observamos,

\footnotetext{
${ }^{21}$ Frehse, Fraya. op. cit., p. 95.
} 
escondidos que estamos em outros cantos da cidade, em outras esquinas com outras companhias. São poucos os livros que proporcionam isso. Mais do que ser conduzido por um "passeio imaginário", Frehse proporciona ao leitor uma espécie bastante singular de "aventura" urbana, antropológica e histórica; uma "aventura" ampla, rica e aberta; uma “aventura", enfim, próxima do sentido que lhe deu Gadamer:

A aventura não é, de forma alguma, apenas um episódio. Os episódios são casos singulares que se enfileiram uns aos outros, que não possuem nenhuma correlação interna e que justamente por esse motivo não tem um significado duradouro. A aventura, ao contrário, embora também interrompa o curso costumeiro das coisas, se relaciona positiva e significativamente com a correlação que interrompe. Por isso a aventura permite que se sinta a vida no todo, na sua amplidão e na sua força. Nisso reside o fascínio da aventura. Dispensa as condicionalidades e os compromissos sob os quais se encontra a vida costumeira. Ousa partir rumo ao que é incerto.

Ao mesmo tempo está consciente do caráter de exceção que é próprio da aventura, e assim continua vinculado ao retorno ao costumeiro para onde a aventura não pode ser conduzida. A gente 'vence' uma aventura, como se fosse um teste ou uma prova, de onde se sai enriquecido e amadurecido. ${ }^{22}$

Completamente diferente às atitudes de Zaluar, este sim um homem que passeou no sentido burguês pela São Paulo de meados do século XIX, não se aventurando em nada, muito pelo contrário, se colocando em relação a cidade e a sua população como um verdadeiro "demônio de Laplace", procurando ver a cidade e seus habitantes de cima, a distância, com visão panorâmica e abrangente e tendo por objetivo mapear os elementos que denotassem o progresso paulista, Fraya Frehse integra-se e integra-nos, enquanto leitores, a cidade e seus transeuntes. Participamos de sua "aventura" de antropóloga assim como participamos das "aventuras" da cidade de fins do Império.

Ao acompanhar Frehse "vemos" e "ouvimos" uma São Paulo cheia de contradições, ambiguidades, tensões, injustiças, privilégios, mas também e principalmente uma São Paulo cheia de vida pulsante, uma vida que começava a tomar o espaço da rua de forma mais efetiva, barulhenta, generalizada, reivindicativa.

Vemo-nos mergulhados numa cidade fronteiriça que não era mais aquela descrita por Zaluar e não era ainda a São Paulo vista por Floreal. Sem o estudo do período entre os anos de 1870 e 1890 é difícil compreender tanto aquilo que percebeu o viajante em meados do século XIX como, principalmente, o que vislumbrou o escritor em 1925. Na cidade dos transeuntes estudados por Fraya Frehse antigas e tradicionais práticas coloniais lançamento de dejetos fecais e domésticos nas ruas e várzeas da cidade, banhos e lavagem

\footnotetext{
${ }^{22}$ Gadamer, Hans-George. Verdade e Método - Traços fundamentais de uma hermenêutica filosófica. Petrópolis: Vozes, 1997, p. 130.
} 
de roupas em rios, criação e venda de animais pelas ruas, festas populares, meios de transportes coloniais e comércio ambulante - começavam a se confrontar e a se amalgamar com elementos e atitudes de relativa modernidade: linhas de bondes tracionados por força animal, água encanada, rede de esgotos, iluminação a gás. É entre esses dois mundos que nos aventuramos com a autora. Foi entre esses dois mundos que começou a se formar, conforme Frehse, a "opinião pública” paulistana.

Não é de forma passiva que acompanhamos Fraya no espaço privilegiado da rua: seu livro é uma proposta aberta ao diálogo, à crítica, a reflexão. Além de "escutarmos" sua "voz" de antropóloga urbana ela deixa que "escutemos" com muita nitidez, e este é um de seus principais méritos, as inúmeras "vozes" de seus diversos transeuntes-interlocutores: são "ecos" tanto das camadas mais humildes da população - carroceiros, cocheiros, tropeiros, quitandeiras, carreiros, escravos e pobres em geral - como das novas e ainda difusas camadas médias da sociedade que começavam a ocupar o espaço da rua. Através de suas "vozes", principalmente das mais humildes, começamos a compreender as bases nas quais seria erigida a metrópole paulista "moderna". Essas "vozes" denunciam o limiar de novas práticas e atitudes urbanas calcadas em exclusivismos, preconceitos, exclusões, monopólios, arrivismos e especulações. Seja através das empresas de transportes, água, esgotos e distribuição de gás que se instalaram e se monopolizaram na cidade, seja através dos descasos e falta de fiscalização do poder público municipal, São Paulo teve grande parte de seu rumo delineado nas duas décadas analisadas por Fraya.

O tempo das ruas na São Paulo de fins do Império é dividido em duas partes principais um tanto quanto independentes uma da outra. Na primeira "Tempos da cidade", a autora apresenta um exaustivo balanço sobre a bibliografia referente a urbanização paulistana de fins do século XIX. Em seu arrolamento de autores que trabalharam direta ou indiretamente essa temática destacam-se estudos de Gilberto Freyre, Sérgio Buarque de Holanda, Florestan Fernandes, Eurípides Simões de Paula, Richard Morse, Caio Prado Júnior, Pierre Mombeig, Ernani Silva Bruno, Odilon Nogueira Mattos, Antônio Cândido, Fernando Henrique Cardoso, Emília Viotti da Costa, Maria Isaura Pereira de Queiroz, Olga R. Moraes Von Simson, Ana Lucia Duarte Lanna, Raquel Rolnik, Maria Cristina Cortez Wissenbach, Maria Cecília Naclério Homem, Maria Inez Marchado Borges Pinto, Paulo César Garcez Marins, Maria Odila Leite da Silva Dias e José de Souza Martins. Fraya 
Frehse além de criar uma síntese de como esses autores pensaram vários aspectos referente a urbanização, ela destaca também os pressupostos teórico-metodológicos pelos quais cada um deles se orientou. Dentro desse amplo panorama de leituras no qual a autora dialoga com textos escritos entre as décadas de 1930 e 1990 ela detecta três concepções básicas ou linhas de abordagem para o processo de urbanização paulistana: estudos que ressaltam as continuidades urbanas e socioculturais; estudos que dão ênfase às rupturas, mudanças e transformações ocorridas no período; e por fim reflexões que procuram estabelecer certa "coexistência tensa e irremediável entre ambas", entre as continuidades e as rupturas, ou seja, entre diversos tempos históricos, ou lembrando Koselleck, a presença em um mesmo período de múltiplas temporalidades. ${ }^{23}$ Dentro desse amplo espectro a autora destaca e diferencia, demonstrando sua importância e seu interesse por pesquisadores que deram ênfase à questão do cotidiano e à dimensão sociocultural da urbanização. Entre eles Fraya compartilha as propostas lançadas por Maria Odila Leite da Silva Dias, José de Souza Martins, Maria Cristina Cortez Wissenbach, Maria Inez Machado Borges Pinto e Paulo César Garcez Marins. No entanto, após essa detalhada síntese e diálogo, a autora esclarece a especificidade de sua proposta:

A questão que esses estudos deixam em aberto e que inspira esta análise se refere em particular, a como as pessoas em seu dia-a-dia, na São Paulo das décadas de 1870 e 1880, percebem essa coexistência de tempos históricos em suas vidas. Para tanto, nada como buscar as soluções inventivas que vão formulando, ao longo do tempo para esse dilema. Elas se costuram em meio à interação entre a contingência da ação e a constância da convenção. ${ }^{24}$

Para atingir esse objetivo, a autora utiliza como fontes, notícias de jornal, Atas da Câmara, Relatórios de Presidentes da Província, memórias, crônicas, relatos de viagem e fotografias com destaque especial para aquelas atribuídas a Militão. É a partir desse farto e fascinante material que Fraya parte ao encontro de seus transeuntes e procura reconstruir o cotidiano das ruas paulistanas de fins do Império. Esta é a segunda e principal parte de seu livro: "Tempos na cidade". Ao "passeio imaginário" propriamente dito ou à "aventura" histórico-antropológica foi reservado todo um sub-capítulo: "Da Varzea ao Collegio, e pela Paulicéa Toda". Em dois outros - "Querelas e Mazelas de um Cotidiano Bem Pouco Cotidiano" e "Transeuntes Paulistanos: sua Alegria, seu Choro" - a autora aprofunda níveis de compreensão acerca dos embates e convivências do transeunte paulistano de fins do

\footnotetext{
${ }^{23}$ Koselleck, Reinhart. Futuro Passado. Para una Semántica de los Tiempos Históricos. Barcelona: Paidós, 1993.

${ }^{24}$ Frehse, Fraya. op. cit., p. 90.
} 
Império entre aquelas atividades sociais classificadas como antigas e aquelas outras consideradas modernas. Aqui são discutidas importantes questões sobre ruralismo e urbanidade, sanitarismo e higienização, urbanização, rusticidade e civilidade, industrialização, reivindicação "popular” e monopólio de empresas urbanas, etc.

Completando o livro, após suas considerações finais a cerca "Do tempo aos espaços - públicos" a autora acrescenta um importante "Glossário dos lugares públicos mencionados". Nesse glossário Fraya informa em ordem alfabética, a denominação atual de antigos logradouros paulistanos.

A São Paulo vislumbrada por Fraya Fehse está entre a cidade colonial e a cidade em processo de metropolização. Como muito bem demonstra a autora, mais do que a substituição do "velho" pelo "moderno" o que se encontrava e até hoje se encontra na história de São Paulo é a constante interpenetração, co-adaptação e interdependência de ambos. Entre a modernidade sonhada por alguns e a modernidade existente, São Paulo sempre foi uma cidade paradoxal, contingencial, ambivalente.

Tiniu o telefone. Era Elza, avisando que ninguém saísse de casa, porque andava sôlta pela cidade uma boiada enfurecida. (...)

Daí a pouco apareceram no nosso quarteirão da Avenida Angélica alguns bois soltos, uns perseguidos, outros perseguindo, um olhando como boi para palácio, outro filosofando, e vários "naquela aspiração de liberdade de que a natureza dotou a todos os animais".

Era uma boiada que se assustara com uma buzina de automóvel, quando no ano de nascimento de Nosso Senhor Jesus Cristo de mil novecentos e trinta e quatro atravessava o perímetro urbano desta mui leal cidade de São Paulo com a devida permissão dos "homens bons" que ainda ocupavam a terra com grã probidade e sabedoria.

Havia gente aflita nas janelas, nas ruas corriam homens armados de guarda-chuvas, outros tentavam forçar portões fechados ou saltar grades, guardas civis de revólver em punho corriam quando os bois se aproximavam, boiadeiros de faca e bombachas tentavam laçá-los. Gente ensangüentava-se porque queria treinar para toureiro.

Vencidos pelo cansaço, sede e falta de alimento, os bois foram reunidos e levados, de olhar triste, para o matadouro, onde receberam a justa punição de seus crimes. ${ }^{25}$

25 Americano, Jorge. São Paulo Nesse Tempo (1915-1935). São Paulo: Edições Melhoramentos, s.d., p. 210. 